\title{
High-rise residential resuscitation: scaling the challenge
}

\author{
Desmond Ren Hao Mao MBBS MMed, Marcus Eng Hock Ong MBBS MPH
}

See also page 413 and www.cmaj.ca/lookup/doi/10.1503/cmaj.150544

$\mathrm{H}$ igh-rise residential buildings present unique challenges to prehospital care providers. In a linked research paper, Drennan and colleagues ${ }^{1}$ show that patients residing on higher floors of high-rise buildings in Toronto had lower survival after out-of-hospital cardiac arrest. Most out-of-hospital cardiac arrests occur in residential areas, and these cases are associated with poorer outcomes than nonresidential cardiac arrests. ${ }^{2,3}$ With global urbanization, increasing numbers of people are living in high-rise buildings in cities such as Toronto, Singapore and Hong Kong. ${ }^{4}$ It is therefore timely to reconsider strategies to manage high-rise cardiac arrest and to consider solutions tailored for the urban setting.

Drennan and colleagues ${ }^{1}$ found that among patients having cardiac arrest on higher floors, there were significantly longer response times to the patient's side, a lower rate of shockable rhythms and overall decreased survival to discharge, relative to those on lower floors. These findings are not surprising.

Three previous observational studies ${ }^{5-7}$ showed that the time from call dispatch to arrival at the patient's side was adversely affected if the call originated from a higher floor. For example, a large observational study showed that the mean time from ambulance arrival on scene to patient contact was 2.8 minutes for people on the first two floors but 3.1 minutes for those on the 3rd to 9th floors and 3.3 minutes for those on the 10th floor or higher. ${ }^{5}$ Two smaller observational studies ${ }^{6,7}$ had similar results, with longer on-scene time for people on higher floors.

Out-of-hospital cardiac arrests in residential dwellings present certain specific challenges. A well-designed population-based study in Osaka, Japan, ${ }^{2}$ showed that patients with cardiac arrest in residential areas had lower rates of witnessed arrest and a lower chance of being found in ventricular fibrillation than those whose cardiac arrest occurred in a public place. These findings were echoed in a retrospective cohort study. ${ }^{3}$ Both studies $^{2,3}$ showed lower survival rates for patients in residential areas, likely because of lower rates of witnessed arrest.
Drennan and colleagues ${ }^{1}$ identified barriers to elevator access as one reason for delayed time to patient contact. Others showed that additional elevator stops happened in $18.6 \%$ of high-rise residential calls, with each stop contributing another 54 seconds to the interval from arrival on scene to arrival at the patient's side, ${ }^{5}$ and that access barriers were present in $33.9 \%$ of all paramedic calls to apartment buildings. ${ }^{7}$ Other access barriers included a requirement for an entry code (67.6\% of all access barriers), lack of directional signs $(82.6 \%)$ and inability to fit the ambulance stretcher into the elevator $(67.9 \%)$. Dedicated special-access elevators ${ }^{5}$ and a universal elevator access key for paramedics have been suggested, but it is not yet known whether such measures would decrease on-scene time.

Although extrication time was not measured in the linked study, ${ }^{1}$ others have postulated that cardiac arrests on higher floors had longer extrication times, which contributed to poorer outcomes. ${ }^{6}$ This factor is likely related to difficulty in accessing the elevator and fitting stretchers into the elevator. ${ }^{7}$ In one small retrospective observational study, ${ }^{8}$ the quality of cardiopulmonary resuscitation (CPR) deteriorated during patient transport, and delivery of CPR in elevators is a particular challenge.

Despite the challenges, there are also opportunities to improve access in high-rise structures. In high-density apartment buildings, residents could be mobilized to provide bystander CPR for
Competing interests:
None declared.

This article was solicited and has not been peer reviewed.

Correspondence to:

Marcus Ong, marcus.ong.e.h@sgh.com.sg

CMAJ 2016. DOI:10.1503 /cmaj.151044 
their neighbours. It might also be cost-effective to deploy public automated external defibrillators. In a large retrospective study using data from Japan's out-of-hospital cardiac arrest registry, ${ }^{9}$ bystander-administered CPR and defibrillation were associated with improved survival.

A direct way to improve response time is to train the family members of those at risk. Goh and associates $^{3}$ suggested a target of one CPR-trained individual per high-risk household, which could be achieved through "prescription" of the CPR training. Others have reported that it is possible and cost-effective to place automated external defibrillators strategically in certain residential locations..$^{10}$ For these devices to be effective in the residential setting, first responders would need to know the location of the nearest unit. A nationwide registry and publicity about device locations directed to local high-rise dwellers could make this an achievable goal.

A key to the puzzle may lie in the use of smartphone technology. A blinded, randomized controlled trial involving nearly 10000 volunteers showed that using mobile-phone positioning to alert volunteers significantly increased rates of bystander-initiated CPR for out-of-hospital cardiac arrest. ${ }^{11}$ By logical extension, volunteers mobilized by smartphone technology could also be employed as escorts, rendering assistance to prehospital providers by decreasing access barriers in high-rise buildings (e.g., holding the elevator for paramedics). Smartphone-enabled geolocation could help pinpoint the exact spot of the patient in complex multilevel buildings and could thereby decrease response times for emergency medical service personnel.

Our own setting, Singapore, is a highly urbanized city where most of the population lives in high-rise apartments. ${ }^{4}$ Here, apartment blocks are organized into residents' committees, with a neighbourhood watch system. Singapore has a multipronged approach to address high-rise residential out-of-hospital cardiac arrests. A large public campaign is currently underway to enrol residents' committees as first responders and to train one million people over the next five years. A national registry of automated external defibrillators linked to a first-responder app has also been established. Defibrillators are being deployed in every other apartment block in six pilot communities. In a city where smartphones are ubiquitous, use of this technology has the potential to link first responders to cardiac arrest victims and to automated external defibrillators in high-rise apartment buildings.

Out-of-hospital cardiac arrests occurring in high-rise residential dwellings present both challenges and opportunities. In this setting, CPR training for building residents who are laypersons and placement of external defibrillators linked by smartphone technology represent opportunities to improve survival.

\section{References}

1. Drennan IR, Strum RP, Byers A, et al. Out-of-hospital cardiac arrest in high-rise buildings: delays to patient care and effects on survival. CMAJ 2016. 2016;188:413-9.

2. Iwami T, Hiraide A, Nakanishi N, et al. Outcome and characteristics of out-of-hospital cardiac arrest according to location of arrest: a report from a large-scale, population-based study in Osaka, Japan. Resuscitation 2006;69:221-8.

3. Goh ES, Liang B, Fook-Chong S, et al. Effect of location of outof-hospital cardiac arrest on survival outcomes. Ann Acad Med Singapore 2013;42:437-44.

4. Introduction: high-rise living in Asian cities. In: Yuen B, Yeh AGO, editors. High-rise living in Asian cities. The Netherlands: Springer Science+Business Media B.V.; 2011:1-8.

5. Silverman RA, Galea $S$, Blaney $S$, et al. The "vertical response time": barriers to ambulance response in an urban area. Acad Emerg Med 2007; 14:772-8.

6. Lateef F, Anantharaman V. Delays in the EMS response to and the evacuation of patients in high-rise buildings in Singapore. Prehosp Emerg Care 2000;4:327-32.

7. Morrison LJ, Angelini MP, Vermeulen MJ, et al. Measuring the EMS patient access time interval and the impact of responding to high-rise buildings. Prehosp Emerg Care 2005;9:14-8.

8. Olasveengen TM, Wik L, Steen PA. Quality of cardiopulmonary resuscitation before and during transport in out-of-hospital cardiac arrest. Resuscitation 2008; 76:185-90.

9. Nakahara S, Tomio J, Ichikawa M, et al. Association of bystander interventions with neurologically intact survival among patients with bystander-witnessed out-of-hospital cardiac arrest in Japan. JAMA 2015;314:247-54.

10. Folke F, Gislason GH, Lippert FK, et al. Differences between out-of-hospital cardiac arrest in residential and public locations and implications for public-access defibrillation. Circulation 2010;122:623-30.

11. Ringh M, Rosenqvist M, Hollenberg J, et al. Mobile-phone dispatch of laypersons for CPR in out-of-hospital cardiac arrest. $N$ Engl J Med 2015;372:2316-25.

Affiliations: Department of Emergency Medicine (Mao), Khoo Teck Puat Hospital, Singapore; Department of Emergency Medicine (Ong), Singapore General Hospital, Singapore; Health Services and Systems Research (Ong), DukeNUS Graduate Medical School, Singapore

Contributors: Marcus Ong conceived and planned the article. Desmond Mao performed the literature search, and both authors analyzed and interpreted data from the identified articles. Desmond Mao wrote the first draft of the manuscript, and both authors revised the manuscript for important intellectual content, approved the final version to be published and agreed to serve as guarantors of the work. 